\title{
EL DESARROLLO HUMANO Y LA FORMACIÓN INTEGRAL EN DISEÑO. CUERPO Y SENSIBILIDAD EN LOS PROCESOS DE CONFIGURACIÓN DE TEJIDOS EPISTEMOLÓGICOS
}

The human development and the integral formation in design.

Body and sensibility in the proceses of configuration of epistemological tissues.

\section{Por: Viviana Polo Flórez ${ }^{1}$}

Docente e investigadora

Programa Diseño de Vestuario

Universidad San Buenaventura de Cali.

Resumen: Este texto plantea un cambio de mirada en la enseñanza del diseño hacia una visión integral de la disciplina. El Humanismo del Diseño podría afianzarse desde la formación del diseñador, acorde con su propio desarrollo, permitiéndole analizar su sentido histórico-subjetivo y sentando las bases de un alfabetismo objetual. Este concepto es entendido como la comprensión consciente y la relación consecuente del creador con el usuario y de la mutua afectación con la realidad material que liga la época y el sujeto en el tiempo. En tal sentido, esta ruta pretende rescatar la subjetividad y el potencial de emergencia de los sujetos, tanto el ser-sujeto que se forma (el diseñador) y que determina lo que serán los objetos, como el ser que los "usa" y con ello re-crea la cultura.

Palabras Clave: Desarrollo Humano, Epocalidad, Subjetividad, Procesos de Diseño, Educabilidad.

\begin{abstract}
This text exposes a change in the view of the design teaching to an integral vision of the discipline. The Humanism of the Design could be supported by the formation of the designer, according with his own development, allowing to analizes his historial-subjective sense and laying the foundations of an objectual alphabetism. This concept is understood as the conscient comprehension and the consequent relationship of the creator and the user and of the mutual afectation with the material reality that ties the epoch and the subject in the time. In that sense, this rout seeks for redeem the subjectivity and the potential of emergency of the subjects.
\end{abstract}

Keywords: Human Development, Epochality, Subjectivity, Design Proceses, Educability. 


\section{Introducción}

Este documento parte de la premisa que asume el Desarrollo Humano como eje esencial de la formación del sujeto que diseña, prevaleciendo el alfabetismo objetual y la época. Esta premisa, situada en la búsqueda de afianzar, comprender y reconocer al Diseño como herramienta de integración y síntesis que potencia la transformación de la realidad, avala la modificación hermenéutica de las narrativas convencionales del entorno y permite la construcción del pensamiento epistémico: un discurso con sujeto / un sujeto con discurso; un objeto con discurso / un discurso con objeto, sujeto y tiempo.

Desde este punto de vista, el desarrollo humano es una dimensión intrínseca de los esquemas educativos generales y se define como el fin y el medio para aprender y educar. Sin embargo, en la clasificación general de los sistemas educativos actuales, encontramos segmentaciones - técnicas, tecnológicas y profesionales - que tienden a estructurar a los denominados analistas simbólicos ${ }^{2}$. Estos validan la diversificación de las ramas de conocimiento, dándoles identidad y haciendo de la educación una función social.

Esta estratificación genera rupturas metodológicas y epistémicas, centrándose en un ideal del hacer y, en particular, acentuando la concordancia de las pedagogías específicas como esos 'ensayos' de la eficiencia programada en el futuro productivo de los sujetos. La estructuración del devenir educativo desde los primeros niveles ha ido perfilando, segmentando y sustrayendo elementos de la esencia del sujeto que podrían resultar desfavorables si se lo analiza desde una óptica humanista y sensible para el desarrollo común de las sociedades.

Así, aspectos como la creatividad, la plasticidad, la flexibilidad y la imaginación con la que aprende (y aprehende) un niño son ignorados o se clasifican según los niveles de formación que, en apariencia, descargan de responsabilidad a las instituciones educativas, pero la trasladan al docente. De esta manera, desde el esquema de educación general y frente a esa malla que promueve especialidades en el Diseño, se suma a una larga lista de opciones que seduce a los futuros técnicos y profesionales (sin importar su clasificación productiva) y, entre ellos, a quienes son sensibles a la estética de los objetos (denominativo común de la creación física que aborda las diferentes especialidades del diseño), a la aventura de lo desconocido y a lo propositivo como medio de supervivencia. En la transición que se da entre los niveles de la formación de la disciplina se devela, indefectiblemente, lo que los esquemas educativos imprimen en el sujeto: rigidez en la búsqueda de aprendizajes y la intención de hacer que los procesos y los resultados sean instantáneos. 
Los responsables de los procesos académicos del Diseño como disciplina, abordamos las temáticas de enseñanza según los perfiles que ofrecen las instituciones educativas (sin importar su nivel). Esto, según un planteamiento orientado hacia la priorización de la 'utilidad social de los egresados', por encima de la formación de aquellos sujetos en quienes prime la vitalidad, la imaginación, la creatividad y la proyectiva. Las pedagogías se dirigen hacia la eficiencia informativa, con fórmulas que supuestamente garantizan el éxito, a través del desarrollo de propuestas materiales que - con nuestros ideales de creadores - creemos necesarias para el medio. Ello, dentro de una óptica antropocentrista - formulada desde la inquietud por cómo sirven los objetos al hombre - que no reconoce la antropoplastia ${ }^{3}$ como base de nuestros modelos de educación. Proceso que permitiría descubrir al sujeto, potenciar su desarrollo, su creatividad y esencia humana.

A la vez, no tomamos como punto de partida la realidad que está fuera de nuestras aulas, donde hay esquemas de preparación -aulas y vivencias previas-. Detrás de todo estudiante hay un sujeto, único y diferente. Cada ser humano 'lee' su hábitat y todo lo que condiciona su entorno de modo diferente, no solo en la perspectiva generacional, también en la cognitiva, la mediática y en la del entorno material particular.

Por otra parte, se olvida que el pensamiento por esencia integrador del Diseño no se refiere solo a lo proyectual, también es parte de una cultura de relación humana con su medio. ${ }^{4}$

\section{El cuerpo y la sensibilidad}

Sobre la estructura humana se centra la razón principal del devenir del diseño. La articulación del ser humano y sus partes permite entrever las diversas ópticas con las que pueden ser abordadas las problemáticas en nuestra disciplina, confiriendo rasgos identitarios de un pensamiento en el que priman la resolución y el bienestar de la especie.

Sin embargo, esta estructura es vista generalmente desde las ópticas de las ciencias que sirven al diseño como plataforma y rotulan así la práctica proyectual. El cuerpo es una parte del ser humano y, en cuanto metáfora, también representa estructuraciones institucionales de diversa índole; la existencia de una cabeza, un tronco y unas extremidades sugiere la comprensión hologramática de la configuración con la que fuimos hechos y con la que comprendemos la organización social.

Este cúmulo de elementos impone, dentro de la enseñanza del diseño, diversas perspectivas que separan dramáticamente el órgano del cuerpo ${ }^{5}$. Esto resulta visible en el uso de enunciados típicos que analogan los conceptos y se envasan de modo corpóreo - dando forma, jerarquía y designación-, suscitando una verdad que pueda ser contrastada, probablemente realizada, probablemente real. 
Esto se torna patente en los "productos" del diseño que abarcan el código comunicativo en diversas presentaciones: la palabra, la imagen y el objeto. De estos elementos la imagen es el cúmulo de representaciones que domina los espacios de comunicación y mensaje; por ende, se la tomará como referencia para el desarrollo de esta idea.

Una imagen puede ser un boceto o una tipografía, o un icono de representación. Así lo considera Zizek ${ }^{6}$, quien la entiende como el lugar donde lo real y lo virtual toman la verdadera dimensión. Ella debe superar la simulación y la imitación ya que, al malinterpretar el universo de la realidad virtual, se empobrece su código para la creación. En sus palabras: "La realidad de lo Virtual, por otra parte, significa la realidad de lo Virtual como tal, de sus efectos y consecuencias reales" (Zizek, 2006:19). Pero no es solo este concepto - el de la virtualidad- el que se presenta en las diversas interacciones tanto del mismo ser como de su relación con otros. Incluye el manejo de sus códigos de información. Estos códigos son relacionales y determinan la ubicación en un espacio, en una postura que sugiere una mirada. Desde este ánguloWeibel (2000:23-33) propone tres elementos para comprender la imagen digital, tomándola como referencia de cobertura del producto a diseñar: la virtualidad, que es el modo como se salva la información, la variabilidad del objeto de la imagen y la viabilidad, que es la manera como despliegan los elementos de la imagen.

Desde esta óptica, la encomienda del diseño sería la de ubicar en esa triada - virtualidad, variabilidad y viabilidad - lo que será necesario para el desarrollo de los seres humanos y todos los sistemas que ellos han generado. En los proyectos de diseño está la base del "suponer" y poner lo que "no existe". De aquí procede el reto de aplicar métodos y metodologías surgidas desde la enseñanza del diseño que movilizan y potencien a ese sujeto educable y que prioricen el sentido de su evaluación ${ }^{7}$ e innovación.

Existe una descorporalización, no solo en los devenires de la desestructuración semántica que se le da al diseño, también en el acto de educar en los factores que convergen desde la sensibilidad humana. El diseño, como disciplina, exige la potencia de un sujeto sensible y creador que recree las instancias de la vulnerabilidad humana. Esto desde una lectura de lo real: su emocionalidad, sus condiciones de vida, sus necesidades, sus anhelos, sus sueños, sus esperanzas y sus metas, adecuadas en el aspecto virtual. La esencia del trabajo metodológico del diseño es proveer escenarios inexistentes, mundos invisibles a los ojos reales que ocupan la interpretación del "buen vivir" y que sitúan el futuro dentro de las posibilidades de realización del ser y la gestión de su conocimiento. Bonsiepe (2000:2) propone como una definición del conocimiento para el diseño:

Knowledge is a fluid mix of framed experiences, values, contextual information, and expert insight that provides a framework for evaluating and incorporating new experiencies and information ${ }^{8}$. 
Sin embargo, desde las aulas hemos dividido los universos que dan la postura política del diseñador según la procedencia y finalidad de realización. Haber destazado el cuerpo epistemológico del diseño, encarnando la especialización en áreas del ser, nos ha dejado multiformes a los ojos de la sociedad que recibe al diseñador, pero amorfos en la infraestructura identitaria del diseño.

Los rasgos que dan el norte al significado del diseño han pasado por los diversos estatutos de desarrollo económico, político y social del mundo. La poiesis ${ }^{9}$, como acto inherente al ser humano, se fue clasificando y mezclando con el desarrollo de su sensibilidad y sus capacidades productivas. Así, en todas las clasificaciones de las diversas etapas de evolución del ser humano, la filogénesis denomina con el prefijo homo ${ }^{10}$ los consecuentes avances o diferenciaciones, por ejemplo entre el "hacer" y el "percibir".

La historia del trabajo se ha ligado a este desarrollo evolutivo del ser humano, convirtiendo sus capacidades en oportunidades de “crecimiento" económico, y como desarrollador y especialista de técnicas, mostrando los atributos artefactuales y transformadores como medida de clasificación de lo que son capaces de hacer sus "partes" corporales. La misma sicología enuncia en sus postulados del desarrollo humano las aptitudes que han de erigir un ser humano en correcto "funcionamiento", utilizando términos como presión, motricidad y coordinación, todos ellos ligados a las capacidades técnicas de los órganos que componen el cuerpo biológico - por ejemplo la relación ojo y mano-, y como base para la estructuración sicosocial -por ejemplo, ser apto para producir-. Le Breton (2002:96), en su Sociología del cuerpo, plantea a manera de crítica, cómo el hombre ha sido el producto de su cuerpo desde la clasificación racial y morfológica de manera que

Las características biológicas del hombre hacen a su posición en el conjunto y que esta es la que le corresponde como un hecho de justicia. En lugar de hacer de la corporeidad un efecto de la condición social del hombre, este pensamiento hace de la condición social el producto directo de su cuerpo (...) El cuerpo se vuelve señalamiento, testigo frecuentemente a cargo de la persona a que encarna. (2002:96)

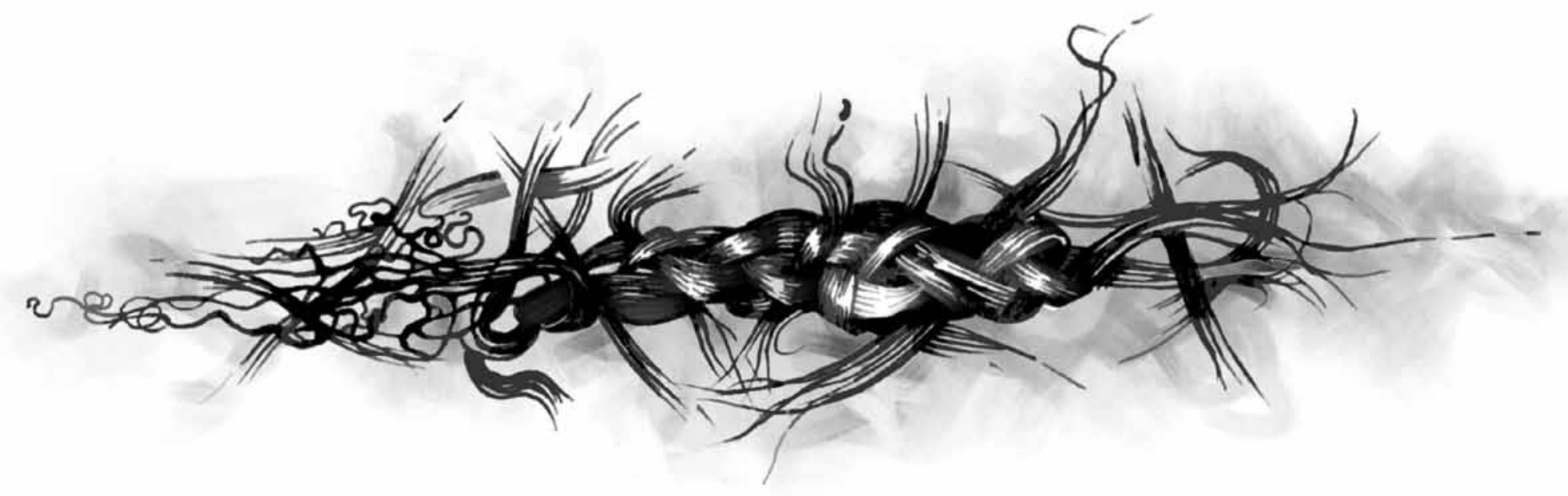


Diversos ejes entrecruzan esta apreciación. Desde la base multidimensional del hombre, por un lado, se alude el cuerpo y su sensibilidad, en complemento de su comprensión del mundo por medio del aprendizaje y ,finalmente, la visión de cómo sus epistemologías internas se van intersecando en la conformación física, social, biológica, sociológica y espiritual. A su vez, se pueden encontrar ejes de relación y de división desde los actos pedagógicos y el devenir habitual de nuestros medios.

Desde la división del conocimiento, las condiciones epistemológicas y sus posteriores adaptaciones han completado 'como herencia' la construcción oficial del saber, dictando el inicio de la universalidad (en donde la supervivencia se da por la cooperación de conocimientos). Como resultado se tienen individuos con altos índices de capacidades cognitivas, memorísticas e información de datos, pero carentes de sensibilidad, intereses o problemáticas más allá de las propias, configurándose un escenario limitado.

Es ésta la óptica con la que seguimos formando en el esquema educativo general: especialidades técnicas donde dejamos de tener memoria del ser particular - cuerpo + espíritu-, y sensibilidades que se direccionan hacia otros rumbos, que deben corporalizarse y encarnarse, pero que están fuera del sujeto encarnado y corpóreo.

La figura analógica en la que nos permitimos basar nuestro devenir profesional, nos acerca a un Homo-Virtus ${ }^{11}$ que se va alejando cada vez más de la materialidad, no solo desde la producción y fruto de sus "manos", sino del sujeto que se aleja hacia otras dimensiones y con el que no se establece un vínculo "real" desde un aula de clase. Hablando en presente, las caracterizaciones líquidas (Bauman) de nuestra sociedad nos dejan entender el mundo como "metáfora de otra cosa", ${ }^{12}$ siendo así por las exigencias de un entendimiento hermenéutico-interpretativo para operar y revestir sobre algo, tomar el aire o el cuerpo de algo que podamos entender.

En esta lógica didáctica cada cual puede creer y crear a su modo. Se brinda libertad dentro de las bases cerradas y se descubre lo propio, dejando una inquietud en el aire: ¿para qué tantos diseñadores haciendo cosas o interfaces para que los otros interpreten lo que a bien tengan? Las verdades no son del todo absolutas en el hecho de lo que está fuera, pero puede suscitarse totalitarista cuando mi percepción es la única que valido, aún en las palabras de otros. Pero la creación, la ordenación, la idea, nacen desde el concepto de la interacción. Desde este ángulo, podemos basarnos en el concepto que sugiere Huizinga (1969:89) desde el cual la interacción inicial y básica del ser humano es el juego. 
En el mito y en el culto es donde tienen su origen las grandes fuerzas impulsivas de la vida cultural: derecho y orden, tráfico, ganancia, artesanía y arte, poesía, erudición y ciencia. Todo esto hunde así sus raíces en el terreno de la actividad lúdica.

El diseño ha tomado posiciones discursivas dicotómicas que dejan al ser-diseñador en ambigüedad, mostrando un cuerpo virtual o un supuesto constructo unificador. Así, sus "resultados" objetuales (desde las diferentes especialidades del diseño), que operan como lógicas de tejidos epistemológicos de fuentes diversas y para situaciones que aún no existen, deben materializarse a través de medios virtuales que alejan la relación del aprendizaje háptico ${ }^{13}$, el proceso constructivo de la conformación y ahondan en la creatividad como una capacidad técnica. Las competencias cognitivas, propias del ser humano, sumadas a los estatutos formalizantes del quién es y que hace, operan como guiones, escenarios y utilerías formales del aprendizaje y de la vida cotidiana. En palabras de Levy (2004:11).

Estamos, pues, en la situación de una especie en la que cada miembro tendría buena memoria, sería observador y astuto, pero que todavía no hubiera logrado la inteligencia colectiva de la cultura por falta de lenguaje articulado. ${ }^{14}$

Lo que nos deja otro eslabón perdido en la búsqueda de la articulación en la epistemología del diseño.15 En esta búsqueda de desnudar el cuerpo del ser, de develarlo en su más pura dimensión para dejar emerger su identidad, lo háptico deja entrever que, como afirma Varela (2000:240) "la mente no está en la cabeza"16 y derrota el postulado que entiende como un sistema operativo el destazado cuerpo metafórico del ser humano.

Al respecto Varela $(2000: 242)^{17}$ continúa su planteamiento:

El organismo como una red de elementos totalmente co-determinados determina que nuestra mente sea, literalmente inseparable, no solo del ambiente externo sino también de aquello que Claude Bernard denominó el Mileu Interieur, el hecho de que no estamos dotados de un cerebro sino de todo un cuerpo ${ }^{18}$.

Y esa identidad que cada ser como sujeto posee, trae consigo las particularidades de las fuerzas internas y motivaciones particulares, las ópticas del mundo, el propio agenciamiento, la semilla y el ser creador. Retomando los elementos que propone Weibel, la triada Virtualidad-Variabilidad-Viabilidad para el manejo de la imagen como dato, y ésta como información, la tecnología háptica basa su pretensión de inclusión del cuerpo desde lo táctil y el gesto. 
El desarrollo de herramientas digitales y su lógica para la integración del ser humano y sus "partes" físicas, ha permitido llegar a la fase del touch y la percepción motora. Sin embargo, las tecnologías que están al servicio de lo cotidiano -tanto en los usos de las personas del común- como en las aulas de clase de diseño - donde se generan estas interfaces- han hecho que la inclusión de lo táctil, aleje el cuerpo de la materia y del disfrute que se da más allá del "toque" de lo material. En diversas especialidades del Diseño, se encuentran insertadas las tecnologías de simulación y representación. Es fácil, por decirlo de algún modo, interpretar el espacio y sus afectaciones; pero es difícil hacerlo con las manos, representarlo, modelarlo, esculpirlo. Es así como en el desarrollo de las prácticas de enseñanza y aprendizaje - estrategias didácticas y pedagógicas- para todas las especialidades del diseño no deberían imponerse los medios netamente tecnológicos, (entendidos como las plataformas de simulación y representación CAD-CAM-CAE), como único medio de transformación. Se debe permitir la complementación del ser humano en su total corporeidad y dinámica, y no como un simple operador sedente en frente de una pantalla y/o siendo observador de la dinámica de un ente que realiza sus operaciones mentales pero fuera de él. Esto, sobre todo, porque son los diseñadores en todas sus especialidades- quienes proponen las interfaces, así que lo que viene por experiencia de aprendizaje es lo que posteriormente se aplica en lo que otros usarán. La premisa, cerrando esta sección y resumiendo el planteamiento es: "no olvidar al cuerpo".

\section{El Alfabetismo Objetual, insumo para el tejido que devela al ser: reconfiguración del Desarrollo Humano}

La denominación de integral abarca las partes de un todo y, en la propuesta del desarrollo de la formación integral, permite hacer un cambio en la perspectiva educativa. Una mirada a la integralidad que permita vincular lo antropocéntrico y lo antropoplástico permitiría afianzar la formación del diseñador y servirse de su sentido histórico-subjetivo para vislumbrar las bases de un alfabetismo objetual. En concreto, se trata de la comprensión consciente y la relación consecuente entre creador y usuario en mutua afectación con la realidad material, de modo que ésta ligue época y contexto.

Cada sujeto es el resultado de su época, es la confluencia de las políticas y el desarrollo que se dejó materializar tanto en los factores de aprendizaje y alimentarios; también en el vestuario, la música, las conformaciones familiares, las características de apertura del mundo y sus lugares. Como docentes entrevemos unos sujetos que se presentan ante nosotros con unas características, las cuales rotulamos como incompetencias o fortunas de acuerdo con el área en la que los recibimos como aprendices. Nos quedamos en la queja de su "mala" ortografía, denotando nuestros propios filtros de sintaxis de la vida, dejando de sintonizar las variables que están fuera de cada uno de nosotros como docentes, y que son el tejido vital de cada aprendiz. 


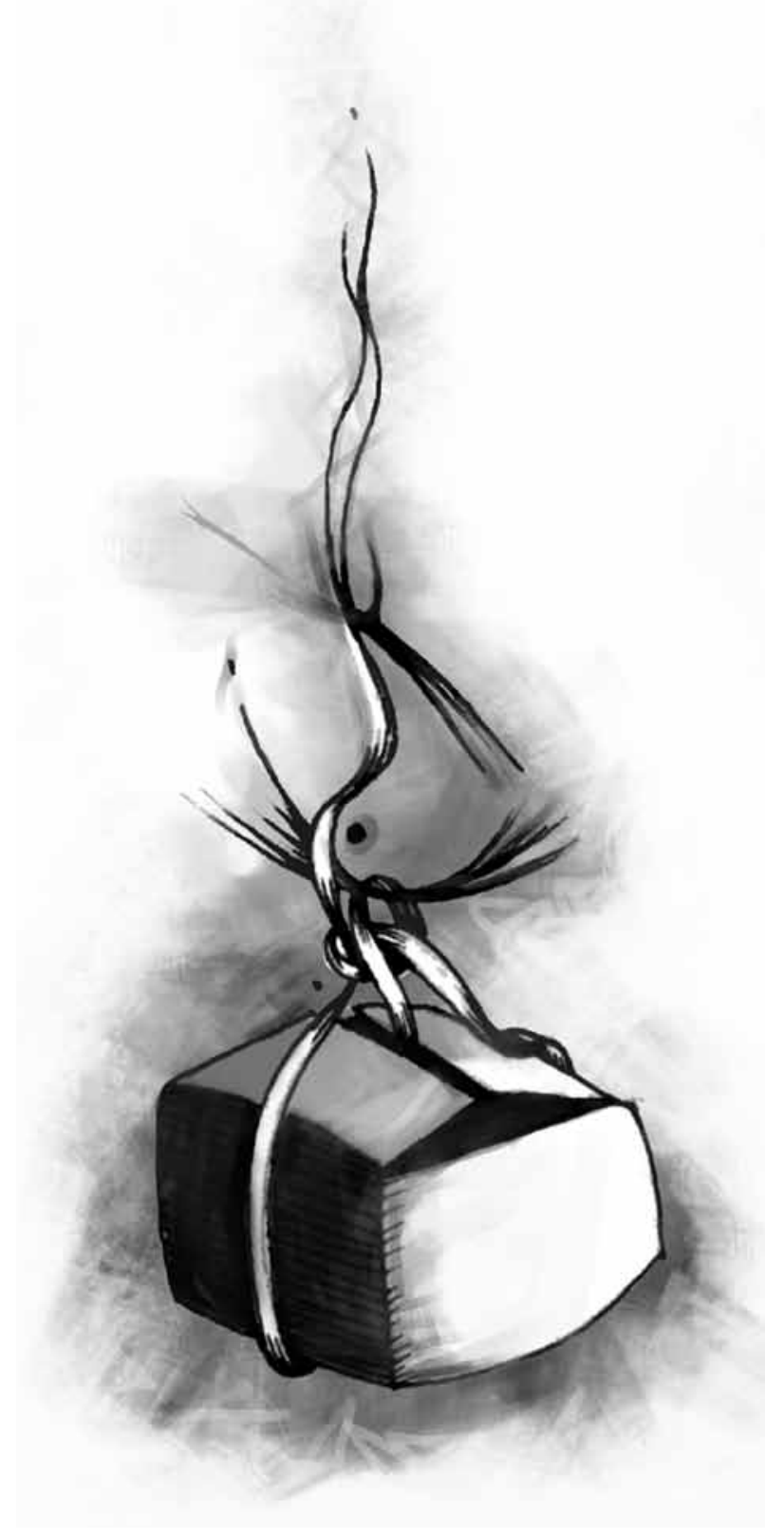

182
Las capacidades particulares con que cada época dota a los sujetos es impronta ineludible en la historia. Podemos hablar del hoy, desde el rasgo formativo que potencia la capacidad de ser multioperativos, o la de saber sintetizar en un símbolo sus emociones. Sujetos en educación en niveles generales, y particularmente en las aulas de diseño, en donde se conforman los códigos de interacción de los usuarios y su mundo. Para Bonsiepe (2000:02), "a simple example serves to illustrate the process of transforming data into information and information into useful knowledge" ${ }^{19}$. Pensamiento de diseño en constante convergencia y divergencia.

Así, en ese puente llamado acto educativo, pretendemos enseñar cómo aprendimos, insistiendo en esquemas quizá ya repetidos o en contraposición, citando estudios de caso que solo referencian la puntualidad de un suceso o idea. Al respecto, dice Lazzarato (2007:42).

El sistema capitalista, a través de la representación y de la significación, produce y distribuye roles y funciones y nos equipa de una subjetividad, nos asigna una individuación: identidad, sexo, profesión, nacionalidad; de manera que todo el mundo está atrapado en una trampa semiótica significante y representativa. Cada uno está asignado a una identidad, y de esta manera somos considerados pero también producidos como sujetos. ${ }^{20}$

En este auto reconocimiento se forma la subjetividad, al formarse desde el ser un sujeto, único e irrepetible.

Para el acto educativo, la inclusión de elementos "sensibles" permitiría un viraje hacia nuevos ejes de relación. Por ejemplo, en la remembranza se podrían encontrar claves del develamiento del ser, a través del reconocimiento de su propio universo físico y material, y del sujeto que presenta su propia identidad y visión del mundo. Ese ser-sujeto que se presenta delante de nosotros está lleno de experiencias que deberían ser la base de su autonomía creativa. La paradoja de los códigos y componentes del aprendizaje que acompañan a una persona desde su niñez, han de determinar sus afinidades y movilizaciones racionales/emocionales ${ }^{21}$. El gusto por un color, un tipo de melodía o la empatía comportamental puede residir en los códigos formal estéticos de sus objetos de la niñez y éstos, con su carga semántica y comunicativa, resuenan en las creaciones, como una especie (inconsciente) de eco-autobiográfico. Colores, sabores, olores, melodías, sensaciones, emergen en una larga cadena entrelazada en cada una de nuestras estructuras filogenéticas, las cuales vamos afianzando o rechazando en el transcurso de la vida. En este punto coincidimos con la postura de Larrosa ${ }^{22}$, para el cual 
La infancia, como acontecimiento, es capaz de borrar tanto el carácter de meramente pasado del pasado como el carácter de meramente futuro del futuro. La infancia del hombre es lo que en el hombre se encuentra antes del sujeto, es decir antes del lenguaje (Skliar y Larrosa, 2001:25).

El alfabetismo objetual comprende no solo el entendimiento de usuario del futuro que habita en ese juego virtual de prever las necesidades, propio del diseño-, sino la codificación de quien crea. Los elementos que ponen en juego las didácticas, si bien corresponden a la infraestructura institucional, innegablemente pertenecen a la época. A modo de arqueología, hacer un barrido de observación de los objetos (entendidos como resultantes de las especialidades del diseño) nos permite tener un inventario que da razón de los seres y las cosas, de ser resultantes de palabras y cosas, de denominativos y designadores que determinan nuestras filias y fobias.

Desde la pregunta de esta autora a Susana Pérez Tort ${ }^{23}$ acerca de quiénes son los nativos digitales en el ámbito educativo, se advierte el siguiente diálogo:

-Pregunta V. Polo: "Hablamos de innovaciones educativas, la mayoría centrada en la tecnología sumado a las relaciones multiculturales y de desarrollo humano y social. ¿Cree usted que habría algún tipo de diferenciación entre los sujetos que pueden acceder a los objetos tecnológicos y los que no, y junto con esto, cree usted que las políticas de difusión educativa teniendo en cuenta la cobertura y conformación permiten que todos los miembros de las nuevas generaciones, se les pueda "adjetivar" como nativo digital?".

Responde Pérez Tort: "Desde el ejercicio de la docencia, advierto que los alumnos (de distintos niveles de consumo) están de hecho alfabetizados, ya que quien no tiene una computadora en su casa, acude a medios públicos. Todos usan correctamente celulares, correo electrónico, chatean, participan de lazos sociales en la red, lo advierto aún en los niveles de menor consumo económico. Podrá no haber acceso a otras cosas, pero se hacen ingentes esfuerzos para adquirir tecnología. El problema es que ese acceso es banal, en tanto y en cuanto falta un eslabón: los profesores que, aferrados al paradigma "ilustrado, libro impreso, biblioteca" son en realidad analfabetos digitales y lo ignoran. No hay todavía formación docente apta para capacitarlos. Los nativos están preparados con su artillería para comprender el mundo de otra manera, para aprender de otra manera, pero no hay docentes a la altura de esos alumnos nativos. 
Los inmigrantes usan los medios pero persisten en el viejo paradigma ilustrado (si toda la información está en la web, el docente debe enseñar a saber cual información es la que vale). Creo que no es tan difícil el acceso a las tecnologías (aunque siguen siendo costosas y las escuelas aún no se equipan suficientemente), pero más difícil es cambiar los docentes, a pesar de que el sistema educativo está en ese proceso.

Así pues, complementando lo dicho, no solo es el medio o la comunicación, sino la interpretación que se da desde el para qué y el cómo del ser-sujeto y aquí el acto educativo se convierte en panal de comportamientos y ambigüedades, no es el tono del objeto, no es el objeto mediador en sí hablando de factores tecnológicos -, es el para qué de lo que se usa, desde lo que se es. Desde la experiencia de ser inmigrante digital lo que nos diferencia es que mientras que los nativos no cuestionan, actúan, los inmigrantes nos preguntamos por qué, interrogamos, teorizamos, aunque usemos los mismos sistemas-. ${ }^{24}$

Pero ¿qué definiría el alfabetismo objetual? Podría ser la comprensión no solo del origen del objeto sino de su uso más allá de la operatividad inmediata; no solo su función práctica sino su función cultural. Es claro que los objetos son las entidades primeras que soportan las interfaces cognitivas de los sujetos: cómo operan, entienden, asimilan y confrontan su propia realidad. Los factores de época se tornan en indicios de 'avance' humano, pero también de entendimiento de las capacidades del sujeto. Aunque parezca paradójico, los objetos que requieren más acción de parte del sujeto se integran a la naturaleza artificial del hombre, permitiendo armonía y experiencia, y no lo absorben ni limitan como lo hacen las interfaces altamente tecnificadas y ausentes de sensibilidad. Las cosas hablan y las personas callan. Las asignaciones de valor las hacen los diseñadores en el momento de crear, pero son validadas por el 'sujeto-usuario'; él finalmente, apropia los elementos materiales, les confiere la propiedad y el permiso real para su existencia. A este movimiento se refiere Foucault.

El lenguaje 'se enraíza' no por el lado de las cosas percibidas, sino por el lado del sujeto en su actividad. Y es posible, entonces, que haya surgido del querer y de la fuerza, más que de esta memoria que duplica la representación. Se habla porque se actúa, no porque al reconocer se conozca. Al igual que la acción, el lenguaje expresa una voluntad profunda. (Foucault, 1997:283). 
Pero entonces, ¿cuáles serían los significados de los objetos?, ¿los que se asignan en una legítima creación o los que se asignan como valor de signo para cada sujeto? Los contextos de permeabilidad del sujeto, en su fase particular de desarrollo, sugieren áreas de aprendizaje que no se establecen solo desde la formalidad. La educabilidad ${ }^{25}$ opera como rasgo de aporte para el crecimiento del ser, da la competencia de un sujeto que está en constante aprendizaje. En este punto las asignaciones de valor se comportan como un bucle idiomático en el que la expresión, el planteamiento y la emoción de por sí están en constante inmersión y emergencia. El lenguaje, como fenómeno colectivo, da al significado y al entendimiento las interfaces y los objetos que se validan como reales y se organizan según nuestra percepción. Y este sentido de lo educable debería tornarse en base para la didáctica del diseño. Estas son narrativas que, más allá de un lenguaje visual, desde sus formas, recogen el sentido háptico y afirman que todo el cuerpo aprende, $\mathrm{y}$ que todo el cuerpo puede diseñar.

Un ejemplo claro que se da en la línea del "aprendizaje" del diseño son las fases de involucramiento con la materia y las fases donde la materia es solo una "virtualidad de lo real”. Como en un esquema de educación básica, es sabido que en los primeros semestres se presenta al aprendiz un sinfín de elementos de relación con los que puede interactuar, los que pueden transformar, con los que se unta, se sensibiliza (hasta en el sentido fisiológico y biológico) y como un infante modifica a su parecer. En el devenir de sus niveles se va alejando más de la materia y va centrando sus procesos de "contacto" a simulaciones virtuales y eficientes de ideas preconcebidas - entendidas como las funciones que un diseñador y/o programador de software ha determinado como herramientas- donde el ser que diseña está cada vez más lejos de la proxémica.

Pensando en el presente, es a primera vista lógico que los nativos digitales se desenvuelvan con soltura y prontitud en este tipo de interfaces de creación, pero el llamado recae en que los procesos para el diseño han de ser centrados en las características sensibles y humanas de quien diseña, de quien manipula, de quien advierte las topografías con eficacia, sus propias iconopoiesis ${ }^{26}$.

\section{Diseño y desarrollo humano como configurador de epistemologías internas: ruta de la gesta y la gestión del conocimiento}

La producción y el consumo disciplinar han puesto sobre la mesa la posibilidad de abordar el aprendizaje del diseñador desde métodos y metódicas que respondan al flujo de información y conocimiento que ha de tenerse sobre un problema o caso de estudio. Y es ahí donde hemos posicionado la esencia del hacer del diseño dentro del aula, sumado a las características formales que exige la institucionalidad de evaluar y juzgar la pertinencia del diseñador en formación. Así, la producción y el consumo son progresos comparativos que se afilian a las escuelas y a los que lideran los procesos directamente en el aula. El desarrollo social y cultural es el elemento que prima como objetivo principal para la resolución y, desde las metódicas generales del diseño, pretende la anulación de los pre-conceptos e invita al individuo desde su subjetividad a "objetivizarse" en la visión del maestro. 
Si bien el planteamiento de la Caja Negra (Jones, 1976) es revaluado hoy por algunos docentes y escuelas, no podemos negar que los procesos cognitivos de los seres humanos pasan por este estadio. Se debe hacer una minuciosa exploración de las orientaciones de las políticas del “diseño de la clase”, en donde todas las pedagogías creadas, establecidas y procuradas por pedagogos y educadores (casi ninguno perteneciente al diseño) asuman la relación con el otro -maestro/aprendiz, aprendiz/maestro - de un modo programático.

Es una clara muestra de lo que se "da” en el aula. Si hiciésemos una arqueología del ser que se enfrenta a un mundo lleno de informaciones, colores, imágenes, formulas y resoluciones, es sensato reconocer que el punto cero de ese sujeto no es nuestro discurso. Desde ahí retomo la metáfora de la Caja Negra, que virtuosamente Jones nos plantea desde la lógica que da la convergencia y la divergencia en el aprehender del conocimiento.

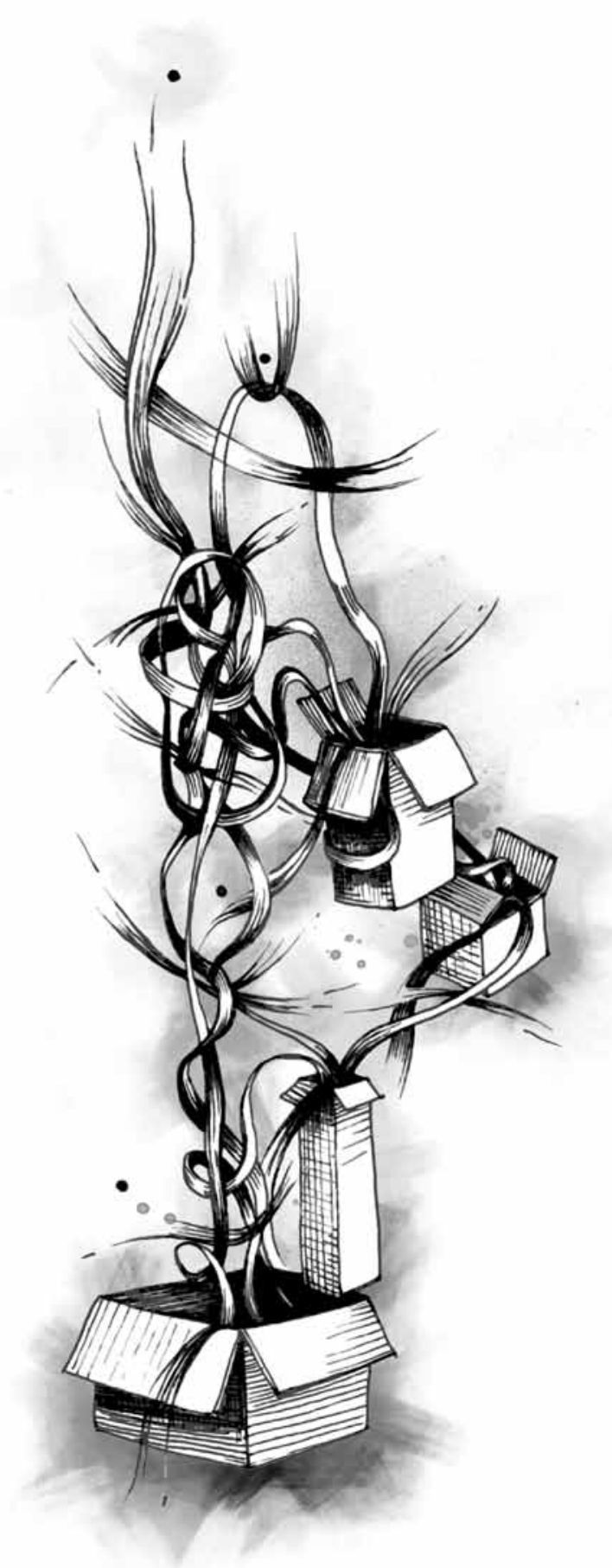

Educación es potenciar la esencia del otro, magnificar sus particularidades, sus actitudes, sus deseos. Es también ver cómo se entremezclan los nuevos saberes con las memorias en sustrato que portan los individuos. El desarrollo humano es el dejar ser, el no coartar, no "enseñar" sino dejar aprender. Esto supone, en la plataforma del diseño, dejar no solo el modo "comfort" o "resolución" como característica de lo que se crea sino como un punto más en pos del descubrimiento del ser.

La distracción en el cuerpo que hay que llenar y administrar nos hace olvidar la corporeidad de los fenómenos y las relaciones; no dejamos fluir la consonancia del ser que aprende respecto a los contenidos (en la lógica de que cada tópico ha de hablar de algo para la formación). Cada ser es una Caja Negra, donde se advierten consonancias y disonancias con nuestro propio parecer; cada semilla pudiese ser anónima y es ahí cuando el maestro debe velar por la epistemología interna de cada sujeto. En la gesta del conocimiento reposan las variantes de lo que serán las personas que educamos y en relevancia sintáctica de lo que será la sociedad a la que cada uno de estos “analistas simbólicos" impactará, virará o invisibilizará el desarrollo humano de la sociedad.

Zemmelman (1992:113) plantea desde la visión del poder del futuro que:"la importancia no reside entonces en encontrar teóricas claramente estructuradas, sino en no restringir el uso de los conceptos a la exigencia de la explicación contenida en ellos”. 
Como conclusión esto podría ser un llamado a un estado de gesta, en el cual los comportamientos ideales y los reales se aprestan a complementarse en las visiones particulares de mundo, que nacen de los individuos y no de las estructuras. Partiendo de esta premisa, el mundo en significancia entra en un estado de metáfora, donde los conocimientos, los datos de información, los insumos de dirección y las finalidades, pueden depender semánticamente de qué o quién los genere, de dónde o para qué se formalicen y, en sí, el acto de conocer entra en una diada de gestionar las gestas, las miradas, la interpretación y el momento, permitiendo hallar el significado del conocimiento: ser y estar.

Notas

${ }^{1}$ Diseñadora Industrial (UTJL). Magister en Educación: Desarrollo Humano (USB-Cali). Docente e investigadora de la Facultad de Arquitectura, Arte y Diseño. Programa Diseño de Vestuario (USB- Cali).

${ }^{2}$ Analistas Simbólicos. Referente a la especialización excesiva dada a las profesiones y oficios. (Gómez Buendía, 1998:3).

${ }^{3}$ Antropoplastia: término acuñado inicialmente por Aldasair Macntyre que señala la plasticidad de la mente y comportamiento humano presenta la contrapartida olvidada de la vulnerabilidad en múltiples dimensiones. (García Carrasco, 2008:3).

${ }^{4}$ Indagación de la autora que ha derivado en tema de investigación. La primera parte de esta indagación fue presentada en el Marco del 2 Encuentro de Enseñanza del Diseño, Universidad de Palermo, el 26 de Julio de 2011, en Buenos Aires. Bajo el Subtítulo:

“Alfabetismo Objetual, la época y el sujeto más allá del estudio de caso".

${ }^{5}$ Concepto sugerido por SlavojZizek a su libro Órganos sin cuerpo, desde la base conceptual de GillesDeleuze.

${ }^{6}$ Zizek, Slavoj. Filósofo esloveno.

${ }^{7}$ Entendido como esa dinámica de la legibilidad, la eficacia y el entendimiento del concepto.

${ }^{8}$ En traducción de la autora: "El conocimiento es como una mezcla de fluidos, compuesto por experiencias, valores, información del contexto y chispazos, los cuales proveen el espacio para hacer la evaluación e incorporación de nuevas experiencias e información".

${ }^{9}$ La noción de Poiesis como estado, proceso y resultante de la capacidad de crear. Referenciado por la autora y basado en el planteamiento de Enrique Dussel en su libro La filosofía de la producción.

${ }^{10}$ Homo: En definición de la Real Academia de la Lengua como IGUAL o SIMIL, desde las definiciones antropológicas la base para la estructuración del hombre en su evolución como especie.

${ }^{11}$ Homo-Virtus: En definición de la autora Homo desde el sentido del hombre como parte de un proceso evolutivo y Virtus como el aspecto de apariencia de estar en otras dimensiones del conocimiento y la interacción.

${ }^{12}$ Frase de la película Il Postino de Michael Radford (1994) basada en la obra literaria Ardiente Paciencia de Antonio Skarmeta (1983).

${ }^{13}$ Relacionando el sentido de lo Háptico, como capacidad corpóreo sensitiva de percepción.

${ }^{14}$ En Levy, Pierre. La inteligencia Colectiva, por una antropología del ciberespacio. OMS - 2004.

${ }^{15}$ Indagación de la autora, que ha derivado en tema de investigación. La primera parte de esta indagación fue presentada en el marco del 13 International Conference of Engineering and ProductDesignEducation - Design Educaction for creativity and bussines innovation, Londres. Inglaterra 8 y 9 de Septiembre de 2011. Bajo el Titulo: "Curriculum Design: Among the ideological and emotional ruptures and sutures", publicado en Inglés.

${ }^{16}$ Varela, Francisco. El Fenómeno de la Vida. Dolmen Ediciones. Chile 2000.

${ }^{17}$ Varela, Francisco. Biólogo chileno, experto en Neurociencias y Ciencias Cognitivas.

${ }^{18}$ Varela, Francisco. El Fenómeno de laVida. Dolmen Ediciones. Chile 2000.

${ }^{19}$ En traducción de la Autora: "Un simple ejemplo sirve para ilustrar el proceso de transformación de datos, en información y esta información en útil conocimiento".

${ }^{20}$ Lazzarato, Mauricio. Biopolítica: Estrategias de Gestión y agenciamientos. Fundación Universidad Central -IESCO y Ediciones Se Cauto Fundación Comunidad. Marzo 2007. Bogotá, Colombia. 
${ }^{21}$ Base del Pensamiento de M.Maffesoli - Sociólogo francés (1944).

${ }^{22}$ Larrosa, Jorge. Profesor de Filosofía de la Educación en la Universidad de Barcelona (España).

${ }^{23}$ Pérez, Tort. Susana. Crítica de arte. Se graduó de la Escuela de Bellas Artes Manuel Belgrano en 1974 y en1977 en la Escuela de Bellas Artes Prilidiano Pueyrredón, hoy Instituto Nacional de Arte de Buenos Aires, Argentina. Profesora de Historia y Arte, artista digital e investigador.

${ }^{24}$ Entrevista hecha en el Marco de la Maestría en Educación: Desarrollo Humano Universidad San Buenaventura de Cali. VIII Cohorte. Septiembre de 2010.

${ }^{25}$ Educabilidad: Concepto basado en la definición dada por Johann Friedrich Herbart, pedagogo alemán (1776-1841) en donde la Educabilidad es:"El concepto fundamental de la pedagogía es la educabilidad del alumno (...). El concepto de educabilidad (ductilidad, plasticidad) es de más vasta extensión. Se extiende casi hasta los elementos de la materia. (...).De la educabilidad volitiva se encuentran rastros en las almas de los animales más nobles. Pero la educabilidad de la voluntad para la moralidad sólo la reconocemos en los hombres".

${ }^{26}$ Se entiende por iconopoiesis la eficacia de la forma para construir mundos en los cuales el perceptor encuentra su identidad. Limitándome a las formas visuales, pueden identificarse tres tipos: cualitativas, identificadoras y simbólicas. Cada una de ellas tiene sus requisitos y proyecta en el mundo condiciones que deben cumplirse para que alcance la eficacia transformadora que en cada caso se le atribuye" (Magariños de Morentin, 2007).

\section{Referencias}

Baudrillard, J. (2004). El Sistema de los Objetos. México: Siglo XXI Editores.

Bauman, Z. (2001). La Sociedad Individualizada. Madrid: Ediciones Catedra.

Bonsiepe, G. (2000). Design as Toll for cognitive Metabolism: From Knowledge production to knowledge presentation. Design as Toll for cognitive Metabolism (págs. 1-13). Milano: International Symposium on dimensions of industrial design research .

Bruyne, Paul; Herman, Jaques; De Schoutheete, Marc;. (1974). La Dinamica de la Investigacion en Ciencias Sociales - Los problemas de la metodologia.

Cassirer, E. (1984). Antropología Filosofica. México: Fondo de Cultura Economica.

Davenport, T., \& Prusak, L. (1998). Working Knowledge. Cambridge Massachusetts, Harvard Universtity Press , 5.

Foucault, M. (1997). Las Palabras y las cosas: Una arqueologia de las ciencias humanas. Mexico: Siglo XXI Editores.

Garcia Carrasco, J. (2008. Lectura pedagógico-moral de los fenómenos sociales: La vulnerabilidad y la fragilidad (pág. 11). Las Palmas de Gran Canaria: Addenda.

Gomez Buendia, H. (1998). Educacion la agenda del siglo XXI - Hacia un desarrollo humano. Colombia: Tercer Mundo Editores.

Gomez, A. D. (01 de Febrero de 2007). monografias.com. Recuperado el 24 de Septiembre de 2010, de http://www. monografias.com/trabajos5/teap/teap.shtml: www.monografias.com

Huzinga, J. (1969). Homo-Ludens. Buenos Aires: Emece Editores.

Jones, J. (1976). Metodos de Diseño. Barcelona: Gustavo Gili Editores.

Jung, C. G. (1991). Arquetipos e Inconsciente Colectivo. Barcelona: Paidos

Kerényi, Karl; Neumann, Erich; Scholen, Gershom; Hillman, James; Ortiz-Oses, Andrés; Mayr, Franz; Panikkar, Raimon; Lanceros, Patxi;. (1994). Arquetipos y símbolos colectivos. Circulo Eranos I. Barcelona: Anthropos - Editorial del Hombre. 
Larrosa, Jorge y Skliar, Carlos. (2001). Habitantes de Babel. Politicas y Poéticas de la Diferencia. Buenos Aires: Laertes.

Lazzarato, M. (2007). Biopolitica: Estrategias de Gestión de agenciamientos. Bogotá: IESCO -Ediciones Se Cauto Fundación Universidad.

Lazzarato, M. (2006). Por una politica menor. Acontecimiento y politica de las sociedades de control.

Madrid: Traficantes de sueños.

Le Breton, D. (2002). Sociologia el Cuerpo. Buenos Aires: Nueva Visión.

Levy, P. (2004). La Inteligencia Colectiva. Washington: OMS .

Maffesoli, M. (1997). Elogio de la Razón Sensible:Una visión intuitiva del mundo contemporaneo. Barcelona: Paidós.

Magariños de Morentin, J. (2007). Iconopoiesis o la eficacia de la forma. Forma y simetria:Arte y ciencia, (pág. 4). Buenos Aires.

Margolin, V., \& Margolin, S. (2002). A “Social Model” of Design: Issues of Practice and Research. Design Issues -

Massachusetts Institute of Technology, 24-30.

Morris, C. W. (1994). Fundamento de la teoria de los signos. Barcelona: Paidos.

Parra Rodriguez, J. (1998). Inspiración. Asuntos intimos sobre creación y creadores. Bogotá: Magisterio.

Pericot, Jordi;. (1991). Pedagogia del Diseño. Barcelona: Editorial Gustavo Gili,S.A.

Piaget, J. (2001). La representación del Mundo en el Niño. España: Ediciones Morata.

Varela, F. (2000). El Fenomeno de laVida. Santiago de Chile: Dolmen Ediciones.

Wallon, H. (1984). La evolución Sicologica del Niño. Barcelona: Grupo Editorial Grijalbo.

Weibel, P. (2000). El mundo como Interfaz. Elementos 40 , 23-33.

Wong, W. (1997). Fundamentos del Diseño Bi y Tri. Barcelona: Gustavo Gilli.

Zemelman, H. (1992). Los Horizontes de la Razón I. Mexico: Anthropos.

Zizek, S. (2006). Organos sin Cuerpo. Sobre Deleuze y consecuencias. España: Pre-Textos.

Recibido: marzo 30 / Aprobado: mayo 21 de 2013

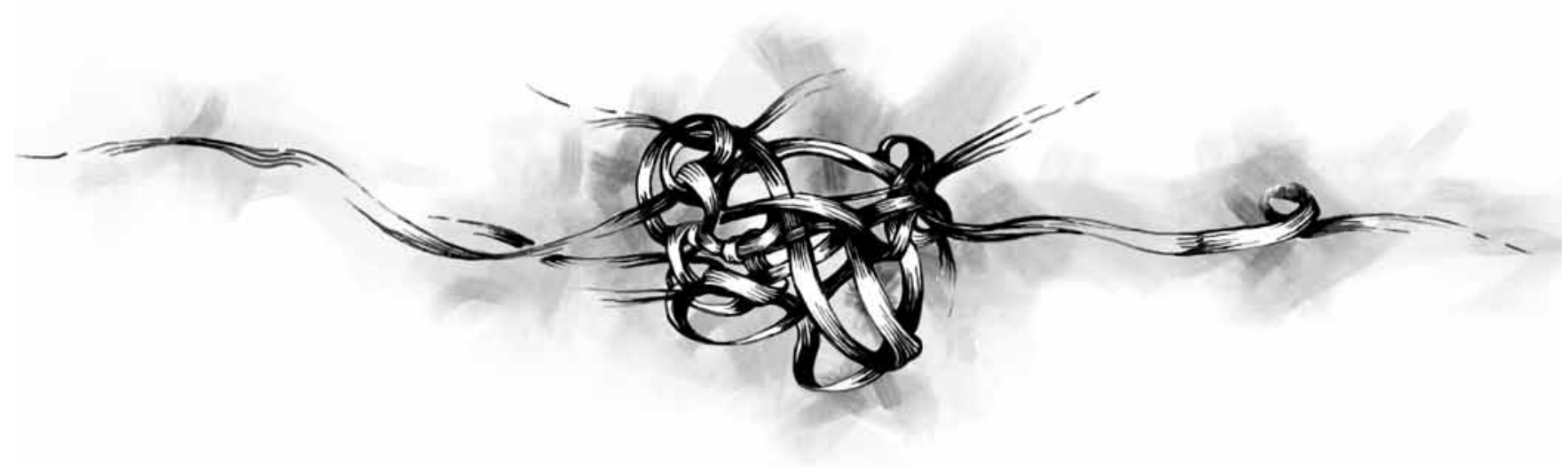

